\title{
8
}

\section{A Team Approach to Supporting Pedagogical Change in University eLearning Environments}

\author{
E. Marcia Johnson \\ University of Waikato, New Zealand
}

In response to recent social, economic, and pedagogical challenges to tertiary-level teaching and learning, universities are increasingly investigating and adopting eLearning as a way to engage and motivate students. This paper reports on the first of a two-year (2009-2010) qualitative case study research project in New Zealand. A snapshot of each of the four 2009 cases and some focused findings are provided, followed by a discussion of implications for researchers investigating technology implementation in tertiary settings.

\section{Introduction and Background to the Research}

$\mathrm{T}$ his paper reports on the first-year findings from a two-year government-funded research project based at the University of Waikato, Hamilton, New Zealand, and which has the overall goal of documenting, developing, and disseminating effective and innovative eLearning practice. A key outcome from the research is to leverage pedagogical change, close participatory gaps for students and lecturers, and contribute to cross-university scholarship in teaching and learning. Four case studies, based in different faculties and subjectareas, were undertaken to investigate pedagogical practices within blended and virtual (fully online) learning environments. What follows is an over- all snapshot of each case followed by brief findings and a discussion of implications."

\section{Research Method and Analytical Framework}

The project was guided by one overall research question: "How are different lecturers/ groups exploiting the potential of Information Communications Technology (ICT)/eLearning to support tertiary-level student learning?" Lecturer reflections were obtained through key informant interviews, while both student and tutor feedback 
were gathered through facilitated focus group discussions. In addition, student reflections about their ICT practices related to their own learning (as opposed to social networking) were gathered through a common online survey designed by the research team. This project received formal university-level human research ethics approval, and all people participated on a strictly voluntary basis.

Consistent with qualitative research, a constant comparison approach to data analysis was followed (Lincoln \& Guba, 1985), but there were some key differences. Although some cases studies did occur simultaneously, not all ran during the same teaching term. However, regardless of who was researching, the entire team met regularly to discuss progress in their case and to share findings and insights. In addition, as interview and focus group data were collected, the team leaders and research assistant (separately) read and re-read the transcripts. Through a process of inductive reasoning, emergent themes were identified (Braun \& Clarke, 2006) and then reported, discussed, and debated at the regular project team meetings. At the end of the first year, the team held a retreat day to consolidate findings and interpretations.

\section{Limitations of the Research}

The research participants represent a convenient sample of lecturers and students in one university and are not representative of possible participants across different settings. Nevertheless, a textured view of instructional practices and multiple participants' beliefs and reactions to the implementation of different ICTs was obtained and, importantly, is consistent with research findings reported elsewhere (Crook, 2008; Helsper \& Eynon, 2009; Means, Toyama, Murphy, Bakia, \& Jones, 2009). While our qualitative case study findings cannot be generalized to a wider population, they can be related to similar higher education teaching contexts and can provide nuanced insights into technology-enhanced teaching and learning practices. However, a key limitation of this study is the possible omission of relevant ideas and perspectives from people who were not included.

\section{Overview of the Four Case Studies}

The four case studies were as follows:

- Earth and Ocean Sciences, first year, 160 students, blended learning

- Professional Education, postgraduate, 7 students, virtual classroom, fully online

- Screen and Media Studies, first year, 220 students, blended learning

- Academic Literacy Skills, pre-degree, 2 classes (40 and 120 students), blended learning

The Earth and Ocean Sciences case study investigated a pedagogical approach in which physical and virtual activities were combined so as to develop students' geo-scientific thinking and practical skills. In particular, this included students' ability to think spatially (Black, 2005), develop a geoscientist's understanding of time, view the earth as a complex and inter-related system, and develop the necessary skills to conduct fieldwork. Google Earth was used by students during lab time and in conjunction with maps and aerial photos to examine landforms and other physical objects around campus and at nearby locations. This lab work helped students develop their skills with Google Earth so that they could visit (virtually) the geographical places referenced in lectures and labs prior to their fieldtrip to a West Coast ocean beach. As part of the fieldtrip activity, students were expected to compare expectations, determined from the virtual pre-visit, to the physical reality of the site, but moreover, students could then revisit the site (using Google Earth) after they returned to the classroom. The lecturer believed that having an ability to enhance physical activities through pre-planning, to compare measurements of spaces obtained in Google Earth with the reality of outdoor places, and to review fieldwork could supplement the pedagogical richness of students' experience.

The Professional Education case study investigated the efficacy of using a real time, web-based virtual classroom environment in the teaching of a fully online postgraduate course 
in the professional practice of eTeaching. Adobe Connect, a web-based synchronous communication application, supports various facilities often found in traditional (physical) meeting rooms and allows users to share, collaborate on, and present work to other participants in real time. The lecturer wanted to determine if participants perceived added value from the shared online experience and developed a sense of belonging to the class group (Moore, 1997). The students' task was to develop, implement, and evaluate an eLearning initiative of their choice, based on a personal or institutional need or opportunity. During the students' first virtual classroom session they presented their initial project ideas and received peer and lecturer feedback about their goals and implementation approach. The second virtual classroom session required students to outline their approach to implementing and evaluating their eLearning initiative, based at least in part on feedback from the first virtual classroom experience. The lecturer hoped that a stronger cohort would develop, which could alleviate feelings of distance or alienation within the fully online instructional environment.

The Screen and Media Studies case involved the adaptation of an existing curriculum from one based on the use of proprietary graphics software, Adobe Photoshop, to one in which an open source software (OSS) graphics package, the GNU Image Manipulation Program (GIMP) was used within Moodle, the University's learning management system (LMS). GIMP offered students freedom of access to a graphics tool so that they could either download the software to their own computers or use it within a university computer lab. Previously, all students had been restricted to use of the proprietary Adobe tool in the labs, which, given the large class size, placed intense scheduling demands on the instructor; there was also no flexibility in the pace at which students had to complete assessed tasks. In the new OSS environment, teaching resources were redesigned so that more confident or experienced computer-using students could work through the revised curriculum materials at their own pace in the Moodle environment. Meanwhile face-to-face instructional time in the computer labs could then be devoted to helping less-experienced students develop the requisite image processing skills needed to complete assignments. The increased flexibility of the learning environment was further supplemented by the removal of the due date for the compulsory GIMP layering assignment so that students could assume control over the pacing of their own work.

The final case study was based in a onesemester, pre-degree academic literacy skills certificate program designed to assist people who had just missed achieving university entrance or people who had been away from formal study for some time and felt unsure about their academic preparedness. Students met their teachers five days a week for classroombased instruction, and teaching resources were predominantly paper-based. Although students in the program were familiar with the use of computers and hand-held mobile technology for social networking, they had weak information literacy competence and often struggled to master skills like paraphrasing, researching, referencing, and the structuring of information into cohesive prose. In order to provide supplementary resources to the in-class teaching, students were introduced to a variety of interactive online workshops, based Moodle and developed at the University for general student learning support. The workshops targeted areas like the essay writing process, paraphrasing, and time management. The instructor believed that students could use these resources, in their own time, to extend and reinforce skills being taught in the classroom, and in addition, to foster a sense of independence and autonomy skills that students would need in formal university degree study.

\section{Discussion and Implications}

A number of key themes have emerged from the project. For example, ICT/eLearning

- provides effective means for dealing with diverse and changing tertiary cohorts, but needs careful curriculum design and monitoring;

- helps expand and transform students' preconceived notions of legitimate subject-area con- 
tent and its representation;

- contributes to and supports students' developing sense of professional identities within their particular fields of study; and

- helps bridge students' conceptual, visual, and spatial thinking from the virtual to the real world.

However, some findings were not as positive as these. For example, not all students enjoyed using technology as it challenged them to conceptualize new and different ways of learning. Moreover, across all case studies technology failed to stimulate the development of learner autonomy in the ways we had anticipated. It is this last finding that will be discussed in more detail here as it links particularly well into the first key theme, which emphasizes the importance of pedagogy.

Because Google Earth is freeware and readily available, the lecturer assumed that learning to use it would be easy and that students could master it on their own. In fact, this was not the case and students reported the need for much more structured guidance from lab tutors in how to use Google Earth to complete the assigned tasks. In Screen and Media Studies, the lecturer's decision to permit students to submit a compulsory assessment at their leisure was not successful. Although the task was given at the beginning of the course, the majority of the assignments were submitted in the last three days of the semester. In fact, students complained about the lack of a deadline and recommended that the lecturer reintroduce one in the following year. In the pre-degree case study, in spite of frequent researcher and teacher requests to students to use the online interactive workshops, almost no-one did. In this case, the student survey data proved illuminating in that the pre-degree students were far more negative than the other research cohorts in their perception of the value of technology for learning. Upon reflection we concluded that this group, which faced a number of challenges related to learning and self-confidence to learn, were possibly not ready for the self-paced independent work required in the online workshops. Rather, students valued and needed a much more traditional, faceto-face relationship with their teacher. In the postgraduate Professional Education case, learners had different feedback regarding learner autonomy. Although these students did report an enhanced sense of connectedness from the virtual classroom experience, they also felt a diminished sense of learner autonomy since they all had to be online at the same time. Synchronous communication can run counter to many students' preferences for asynchronous online learning in their own time, at their own pace. This finding can have important implications for the design of similar fully online programs.

\section{Conclusion}

As stated earlier, the findings from this research are consistent with those reported elsewhere (Blin \& Munro, 2008; Garrison \& Akyol, 2009), and are centered on issues of pedagogy. What was particularly valuable in this project, however, was how the 'team environment' afforded the researchers multiple opportunities to discuss and 're-think' their pedagogy and technological assumptions. In particular, team members realized the importance of contextualizing software tools within the learning expectations of the specific cohort (from pre-degree to postgraduate) and students' competencies and literacies. In addition, although all of the researchers were experienced computer-users, the degree of up-skilling involved in preparing for teaching and using new software within their cases was nontrivial. Each researcher needed to test their software, adapt it to their teaching context, and in most cases, prepare documentation to accompany software use - making the initial setup time considerable. We would conjecture that for many academics, for which eLearning is not a top priority, such demands could present an insurmountable hurdle. On several occasions in project meetings, team members remarked that it was their determination to make the eLearning approaches succeed that helped maintain their motivation, but they also stated that it was the presence and encouragement of the larger group that 
inspired and encouraged them to persevere.

A challenge then for tertiary institutions will be to create teaching and learning environments that encourage, support (with appropriate levels of resourcing), and reward research that focuses on enhancing pedagogical change and improved learning outcomes regardless of the discipline. In addition, there must be support for innovative ICT/ eLearning pedagogy so that it is not considered a time-consuming 'add-on' to lecturers' work, but is a valued component of tertiary pedagogy. Although tertiary institutions expect staff to be active researchers within their particular subject-area contexts, there often appears to be less encouragement or value assigned to research that explicitly relates to deeper knowledge of pedagogy in its own right. Developing institutional structures within which crossdisciplinary conversations can flourish will extend and deepen tertiary pedagogy and contribute to the scholarship of teaching and learning (Shulman, 1999; Whitworth, 2006) so that meaningful learning can occur - arguably the intended objective of all pedagogical undertakings.

\section{Acknowledgements}

The author gratefully acknowledges funding support from the Teaching and Learning Research Initiative, New Zealand Council for Educational Research, Wellington, New Zealand.

\section{References}

Black, A. (2005). Spatial ability and Earth Science conceptual understanding. Journal of Geoscience Education, 53(4), 402-414.

Blin, F. \& Munro, M. (2008). Why hasn't technology disrupted academics' teaching practices? Understanding resistance to change through the lens of activity theory. Computers and Education, 50, 475-490.

Braun, V., \& Clarke, V. (2006). Using thematic analysis in psychology. Qualitative Research in Psychology, 3, 77-101.

Crook, C. (2008). Web 2.0 technologies for learning: The current landscape: Opportunities, challenges, and tensions. Retrieved from http://www.becta.org.uk

Garrison, D.R. \& Akyol, A. (2009). Role of instructional technology in the transformation of higher education. Journal of Computing in Higher Education, 21, 19-30.

Helsper, E.J. \& Eynon, R. (2009). Digital natives: Where is the evidence? British Educational Research Journal, 56(3), 503-520.

Lincoln, Y.S. \& Guba, E. (1985). Naturalistic inquiry. Beverly Hills, CA: Sage Publications.

Means, B., Toyama, Y., Murphy, R., Bakia, M., \& Jones, K. (2009). Evaluation of evidence-based practices in online learning: A meta-analysis and review of online learning. Center for Technology in Learning, U.S. Department of Education. Retrieved from http://www. ed.gov/about/offices/list/opepd/ppss/reports. html

Moore, M. (1997). Theory of transactional distance. In D. Keegan (Ed.), Theoretical principles of distance education (pp. 22-38). New York: Routledge.

Shulman, L.S. (1999). Visions of the possible: Models for campus support of the scholarship of teaching and learning. Retrieved from http:// www.carnegiefoundation.org/elibrary/ visions-possible-models-campus-supportscholarship-teaching-and-learning

Whitworth, W. (2006). Dynamic but prosaic: A methodology for studying e/learning environments. International Journal of Research and Method in Education, 29(2), 151-163. 


\section{Biography}

E. Marcia Johnson has a Ph.D. in Educational Technology from the University of Toronto. She is currently Director, Student Learning, Faculty of Education, University of Waikato, Hamilton, New Zealand. 